\title{
OESOPHAGUS
}

\section{Effect of sildenafil on oesophageal motor function in healthy subjects and patients with oesophageal motor disorders}

\author{
A J Eherer, I Schwetz, H F Hammer, T Petnehazy, S J Scheidl, K Weber, G J Krejs
}

See end of article for authors' affiliations

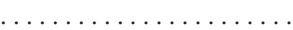

Correspondence to: A J Eherer,

Avenbruggerplatz 15

A-8036 Graz, Austria;

andreas.eherer@kfunigraz. ac.at

Accepted for publication 7 August 2001

\begin{abstract}
Background and aims: Sildenafil blocks phosphodiesterase type 5 which degrades nitric oxide (NO) stimulated $3^{\prime} 5^{\prime}$-cyclic monophosphate (cGMP), thereby relaxing smooth muscle cells in various organs. We used sildenafil as a tool to investigate the role of the NO-cGMP pathway in the oesophagus of healthy volunteers and patients with hypercontractile oesophageal motility disorders.

Methods: Six healthy male volunteers participated in a randomised double blind study on two separate days before and one hour after oral intake of either sildenafil $50 \mathrm{mg}$ or placebo. Oesophageal manometry was performed to determine vector volume of the lower oesophageal sphincter (LOS) and pressure amplitudes of the oesophageal body. Four of the volunteers underwent 12 hour ambulatory oesophageal manometry on two separate days, once with sildenafil $50 \mathrm{mg}$ and once with placebo. An activity index for spontaneous swallowing was calculated for every hour of the study. Eleven patients with hypercontractile oesophageal motility disorders took part in an open study of the effect of $50 \mathrm{mg}$ sildenafil on manometric features of their disorder and on the clinical response to sildenafil taken as required.

Results: In healthy subjects, sildenafil significantly reduced LOS pressure vector volume and pressure amplitudes in the distal half of the oesophageal body. In three of four subjects the inhibitory effect of sildenafil lasted at least eight hours. In nine of 11 patients, manometric improvement after sildenafil was observed but only four had an improvement in oesophageal symptoms with sildenafil taken as required. Two of these four patients however experienced side effects and did not want to continue treatment.

Conclusions: Sildenafil lowers LOS pressure and propulsive forces in the body of the oesophagus of healthy subjects as well as in patients with nutcracker oesophagus, hypertensive LOS, and achalasia. The effect of sildenafil on the oesophageal body may last for up to eight hours in healthy volunteers. A subset of patients with hypertensive LOS or nutcracker oesophagus may benefit from sildenafil but side effects are a limiting factor.
\end{abstract}

$\mathrm{N}$ itric oxide (NO) is widely recognised as a major inhibitory neurotransmitter in the gastrointestinal tract. ${ }^{1}$ It is a non-traditional transmitter as it does not appear to utilise a receptor on the cell membrane of effector cells. Instead, NO activates soluble guanylate cyclase, enhancing production of guanosine $3^{\prime}, 5^{\prime}$-cyclic monophosphate (cGMP). This in turn activates cGMP dependent protein kinase which mediates most of the postjunctional responses attributed to NO dependent neurotransmission. ${ }^{2}$

The NO-cGMP pathway can be influenced by the phosphodiesterase inhibitor sildenafil which is used to treat erectile dysfunction. ${ }^{3}$ It acts by blocking phosphodiesterase type 5 (PD5) that degrades NO stimulated CGMP. ${ }^{4}$ Sildenafil therefore results in accumulation of NO stimulated cGMP, which in turn has inhibitory effects on smooth muscle cells of the arterioles in the human corpus cavernosum ${ }^{5}$ and of other blood vessels as well as of the gut. ${ }^{6}$

NO is a principal neurotransmitter released after deglutition by non-adrenergic non-cholinergic inhibitory neurones. Through production of $\mathrm{CGMP}^{7} \mathrm{NO}$ has been shown to cause relaxation of the lower oesophageal sphincter $(\mathrm{LOS})^{8-12}$ and to regulate peristaltic contractions in various animal species and in humans. ${ }^{92-14}$ The observations reported so far are however conflicting, depending on the species and experimental design. Previous in vivo studies in the human oesophagus have focused on the consequences of reducing the effect of NO by either removing $\mathrm{NO}$ by haemoglobin ${ }^{12}$ or inhibiting its production with $\mathrm{N}$-monomethyl-L-arginine (L-NMMA). ${ }^{910}$ These studies have produced contradictory results. It has recently been shown that sildenafil augments the effect of NO in patients with achalasia, ${ }^{15}$ a disease which is characterised by a defect of NO neurones. ${ }^{16}$ Although there was improvement in manometric parameters with sildenafil, it was not reported whether patients with achalasia experienced symptomatic relief after they received sildenafil.

The aim of our study was to use sildenafil to investigate the NO-cGMP pathway in vivo in humans by augmenting the normal effects of NO through inhibition of cGMP destruction by PD5. We studied the effect on peristaltic motility of the body of the oesophagus and effects on the LOS in normal subjects and in patients with hypercontractile oesophageal motility disorders. Patients in whom motility studies suggested that they might benefit from sildenafil were treated on an as needed basis.

\section{MATERIALS AND METHODS}

\section{Normal subjects}

Normal subjects (six males; aged 26-30 years) reported to the manometry laboratory after an overnight fast. All subjects

Abbreviations: cGMP, guanosine 3'5'-cyclic monophosphate; LOS, lower oesophageal sphincter; L-NMMA, N-monomethyl-t-arginine; NO nitric oxide; PD5, phosphodiesterase type $5 ; \mathrm{rHb}$, recombinant haemoglobin; $\mathrm{Al}$, activity index. 


\begin{tabular}{|c|c|c|c|c|c|c|}
\hline $\begin{array}{l}\text { Patient } \\
\text { No }\end{array}$ & Sex & Age & Major symptoms & $\begin{array}{l}\text { Manometric features before } \\
\text { sildenafil }\end{array}$ & $\begin{array}{l}1 \mathrm{~h} \text { after sildenafil } \\
50 \mathrm{mg}\end{array}$ & Comments \\
\hline 1 & $\mathrm{~F}$ & 54 & Heartburn and dysphagia & $\begin{array}{l}\text { Nutcracker oesophagus } \\
\text { Corpus amplitudes up to } 140 \mathrm{~mm} \mathrm{Hg} \\
\text { Duration of pressure waves up to } 10 \mathrm{~s} \\
\text { LOS pressure } 141 \mathrm{~mm} \mathrm{Hg}\end{array}$ & $\begin{array}{l}\text { Below } 60 \mathrm{~mm} \mathrm{Hg} \\
\text { Below } 5 \mathrm{~s} \\
27 \mathrm{~mm} \mathrm{Hg}\end{array}$ & $\begin{array}{l}3 \text { weeks prn treatment } \\
\text { Withdrawel because of ineffectiveness }\end{array}$ \\
\hline 2 & M & 56 & Regurgitation & $\begin{array}{l}\text { Primarily oesopageal spasm, } 2 \times \text { Botox } \\
\text { LOS pressure } 45 \mathrm{~mm} \mathrm{Hg}\end{array}$ & No change & $\begin{array}{l}2 \text { weeks treatment, ineffectiveness } \\
\text { Dizziness }\end{array}$ \\
\hline 3 & M & 39 & Dysphagia & $\begin{array}{l}\text { Vigorous achalasia } \\
\text { Corpus amplitudes in body } 81 \pm 20 \\
\mathrm{~mm} \mathrm{Hg} \\
\text { LOS pressure } 35 \pm 10 \mathrm{~mm} \mathrm{Hg} \\
\text { Relaxation of LOS } 40 \%\end{array}$ & $\begin{array}{l}34 \pm 7 \mathrm{~mm} \mathrm{Hg} 41 \% \\
17 \pm 4 \mathrm{~mm} \mathrm{Hg} 48 \% \\
38 \%\end{array}$ & $\begin{array}{l}10 \text { days treatment, ineffectiveness } \\
\text { Headaches! } \\
\text { Successful dilatation }\end{array}$ \\
\hline 4 & $\mathrm{~F}$ & 27 & Dysphagia & Hypertensive LOS $60 \mathrm{~mm} \mathrm{Hg}$ & Below $20 \mathrm{~mm} \mathrm{Hg}$ & $\begin{array}{l}3 \text { days treatment, ineffectiveness } \\
\text { Headaches and fatigue }\end{array}$ \\
\hline 5 & $\mathrm{~F}$ & 57 & Dysphagia & Hypertensive LOS: $80 \mathrm{~mm} \mathrm{Hg}$ & $16 \mathrm{~mm} \mathrm{Hg}$ & $\begin{array}{l}\text { Under } 25 \mathrm{mg} \text { sildenafil no symptoms. } \\
>4 \text { months. No side effects. } \\
\text { Nifedipine causes dizziness }\end{array}$ \\
\hline 6 & $\mathrm{~F}$ & 37 & Dysphagia & $\begin{array}{l}\text { Achalasia } \\
\text { LOS } 48 \mathrm{~mm} \mathrm{Hg}\end{array}$ & $18 \mathrm{~mm} \mathrm{Hg}$ & $\begin{array}{l}4 \text { days treatment, no effect } \\
\text { Successful Botox injection }\end{array}$ \\
\hline 7 & $\mathrm{~F}$ & 54 & Dysphagia and heartburn & $\begin{array}{l}\text { Corpus: segm. simult. contr. } 70 \mathrm{~mm} \\
\mathrm{Hg} \\
\mathrm{LOS} 76 \mathrm{~mm} \mathrm{Hg}\end{array}$ & $\begin{array}{l}\text { No obvious contraction } \\
10 \mathrm{~mm} \mathrm{Hg}\end{array}$ & $\begin{array}{l}10 \text { days treatment, dysphagia } \\
\text { improved, however sleep disturbances }\end{array}$ \\
\hline 8 & $\mathrm{~F}$ & 36 & Dysphagia & $\begin{array}{l}\text { Nutcracker: corpus ampl. up to } 160 \\
\mathrm{~mm} \mathrm{Hg} \\
\text { Duration of pressure wave }>9 \mathrm{~s} \\
\text { LOS post-deglutitive }>120 \mathrm{~mm} \mathrm{Hg}\end{array}$ & $\begin{array}{l}60 \mathrm{~mm} \mathrm{Hg} \\
\text { Below } 4 \mathrm{~s} \\
\text { LOS } 20 \mathrm{~mm} \mathrm{Hg}\end{array}$ & $\begin{array}{l}1 \text { week treatment, dysphagia } \\
\text { improved, } \\
\text { However feeling of tightness } \\
\text { in the chest at night }\end{array}$ \\
\hline 9 & M & 49 & Dysphagia & $\begin{array}{l}\text { Achalasia, LOS } 71 \mathrm{~mm} \mathrm{Hg} \text {, relax } \\
27 \%\end{array}$ & No change & No treatment \\
\hline 10 & $\mathrm{~F}$ & 41 & $\begin{array}{l}\text { Dysphagia, heartburn, and } \\
\text { COPD }\end{array}$ & $\begin{array}{l}\text { Nutcracker: post-deglut. LOS } 65 \mathrm{~mm} \\
\mathrm{Hg} \\
\text { Corpus amplitudes up to } 160 \mathrm{~mm} \mathrm{Hg} \\
\text { Duration of pressure wave }>9 \mathrm{~s}\end{array}$ & $\begin{array}{l}\text { Below } 20 \mathrm{~mm} \mathrm{Hg} \\
\text { No copus motility } \\
\text { detectable }\end{array}$ & $\begin{array}{l}>4 \text { weeks, dysphagia and heartburn } \\
\text { Improved, better effect than diltiazem }\end{array}$ \\
\hline 11 & M & 56 & Dysphagia & $\begin{array}{l}\text { Nutcracker: corpus ampl. up to } 300 \\
\mathrm{~mm} \mathrm{Hg} \\
\text { Duration of pressure wave up to } 19 \mathrm{~s} \\
\text { LOS up to } 60 \mathrm{~mm} \mathrm{Hg}\end{array}$ & $\begin{array}{l}\text { Below } 65 \mathrm{~mm} \mathrm{Hg} \\
\text { Below } 3 \mathrm{~s} \\
\text { LOS } 10 \mathrm{~mm} \mathrm{Hg}\end{array}$ & 4 days treatment, no effect \\
\hline
\end{tabular}

were healthy, none had a history of oesophageal disease, and none was taking any drugs. After informed consent had been obtained, oesophageal manometry was performed as described below. Then, in a randomised double blind fashion, subjects swallowed either sildenafil $50 \mathrm{mg}$ or, on a separate day, placebo with water. Blinding was achieved by placing the sildenafil tablet into a gelatine capsule of appropriate size. The empty capsule was used as placebo. One hour after intake of medication or placebo a second manometry study was performed. Heart rate and blood pressure was monitored before and after the procedure. On the following day, subjects returned to the laboratory and were asked about symptoms and side effects. They were also asked to guess whether they had received the active drug or placebo. This was done to assess whether the quality of blinding was influenced by the pharmacological effects of sildenafil. The studies with placebo and sildenafil were 2-7 days apart. Both subjects and investigators were blinded to the study drug.

Manometric studies were performed in a standardised fashion. Oesophageal motility was recorded with a six lumen manometric probe (three side holes at the tip, three side holes at $5 \mathrm{~cm}$ intervals above). The catheters were perfused at a rate of $3 \mathrm{ml} / \mathrm{h}$ with distilled water by a pneumohydraulic low compliance capillary infusion system (Biomedicals Inc., Ventura,
California, USA) and connected to pressure transducers (PVB Medizintechnik, Kirchsee, Germany) and a Synectics polygraph HR (Medtronic Functional Diagnostics, Skovlunde, Denmark). The probe was passed transnasally into the gastric lumen and pulled back in $1 \mathrm{~cm}$ steps to determine LOS margins. Then the tip of the tube was positioned at the respiratory inversion point and pressure amplitudes (peak values) of the oesophageal body were recorded while subjects swallowed 10 $\mathrm{ml}$ of water. At least 10 wet swallows were performed. Then the tube was withdrawn by $5 \mathrm{~cm}$ and wet swallows were repeated. Measurements at $5 \mathrm{~cm}$ intervals were repeated until the upper oesophageal sphincter was reached.

The tube was replaced by an eight lumen tube (all side holes at the tip) to perform a rapid pull through over the region of the LOS to calculate the sphincter vector volume of the LOS (Synectics catheter puller, $1 \mathrm{~cm} / \mathrm{s}$, expiratory state of the subjects during the 10 second pull through, Polygram for Windows 2.04, overall length $10 \mathrm{~cm}$, segmental length 0.1 $\mathrm{cm})$.

Four of the six volunteers underwent 12 hour ambulatory oesophageal manometry on a placebo day and on a sildenafil day ( $\mu$ Digitrapper; Synectics Medical, Stockholm, Sweden). Pressure sensors were located 5, 10, and $15 \mathrm{~cm}$ above the LOS. 

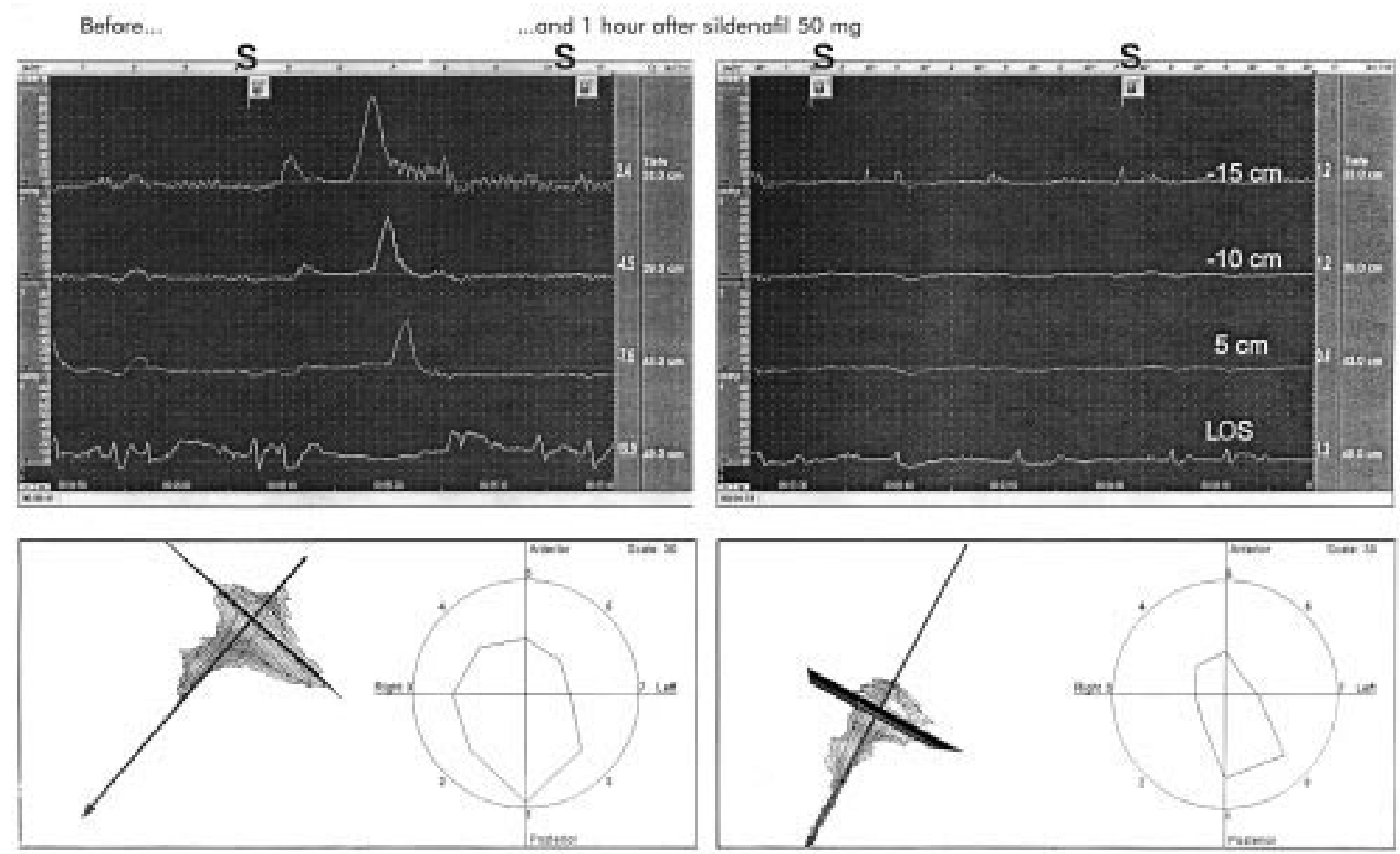

Figure 1 Example of manometric tracings of the oesophageal body and lower oesophageal sphincter (LOS) in a normal subject before and after $50 \mathrm{mg}$ sildenafil. There was a marked decrease in the amplitude of peristaltic contractions and LOS pressure in response to sildenafil. On the bottom, the shaded areas reflect LOS vector volume which was decreased by sildenafil. S, swallow.

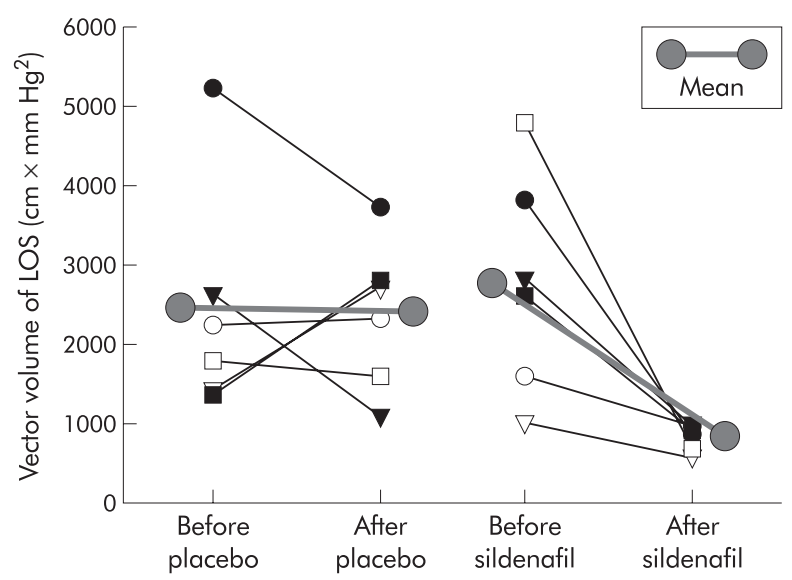

Figure 2 Vector volume of the lower oesophageal sphincter (LOS) in normal subjects before and after placebo or sildenafil.

Placebo or sildenafil $50 \mathrm{mg}$ was ingested three hours after the start of the study.

\section{Data analysis}

The effects of sildenafil and placebo on vector volume, pressure amplitudes of wet swallows, and propagation of swallows in the oesophageal body were calculated as the difference between pre and post drug studies (Wilcoxon test). A $\mathrm{p}$ value of less than $5 \%$ was considered to be significant. To calculate swallow propagation, we determined time intervals between amplitudes at the recording sites, which were spaced at $5 \mathrm{~cm}$ intervals in the oesophageal body.

For each hour of the 12 hour ambulatory study, an activity index (AI) was calculated by multiplying mean pressure amplitudes of spontaneous swallows by the number of swallows. Contractions were considered to be swallows when they showed propagation on the three sites of measurement. Eating and sleeping periods were excluded. During the control day large diurnal variations in AI were observed. Therefore, the AI value for each hour on the sildenafil day was related to the AI of the respective hour on the control day. This was achieved by calculating the relation between AIs for each respective hour on the control and sildenafil days, and expressing the result as the relation of the two AIs in per cent (see fig 6). A relative AI of $100 \%$ therefore represents the same contractile activity on the sildenafil day compared with contractile activity during the respective hour of the control day. Relative AIs of less than 100\% indicate that contractile activity was decreased on the sildenafil day compared with the control day.

\section{Patients}

Eleven patients with achalasia, hypertensive LOS, nutcracker oesophagus, or oesophageal spasm were recruited from our outpatient clinic. All had a longstanding history of either dysphagia or heartburn. Patient characteristics are shown in table 1. Most cases were initially treated by their referring physicians as gastro-oesophageal reflux. When proton pump inhibitors failed to improve the patient's condition, further tests such as manometry were performed to establish a clear diagnosis.

Stationary oesophageal manometry with a six lumen manometry probe was performed before and one hour after sildenafil $50 \mathrm{mg}$ following the same protocol as in normal subjects. Vector manometry was not performed in patients so as to reduce the number of oesophageal intubations. During the manometry study, we focused on the main manometric features that have been used to describe motility disorders such as oesophageal spasm, nutcracker oesophagus, hypertensive LOS, or achalasia, namely the amplitude and duration of amplitudes in the oesophageal body, and basal pressure and relaxation of the LOS. ${ }^{17}{ }^{18}$ After baseline manometry, the manometry tube was withdrawn and $50 \mathrm{mg}$ sildenafil was given orally. Patients were again intubated with the manometry 

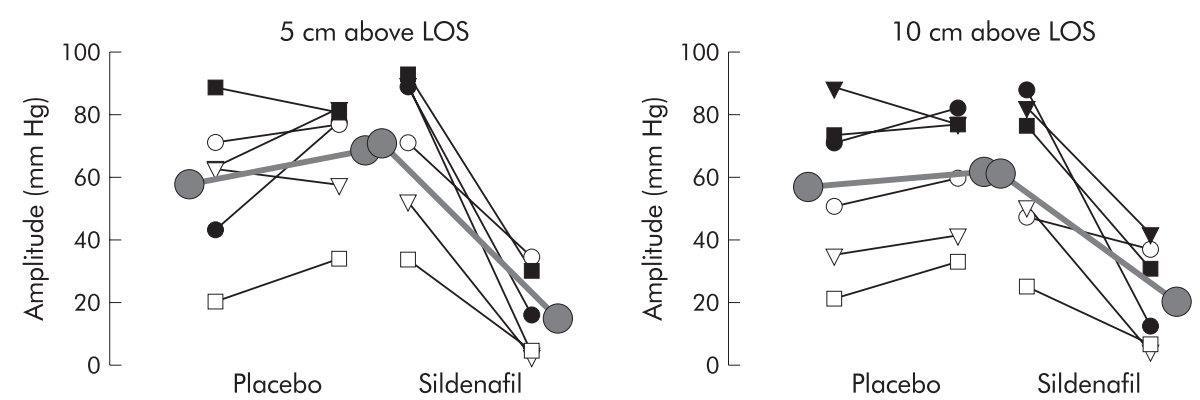

Figure 3 Amplitude of oesophageal contractions in normal subjects at different levels, before and after placebo or sildenafil. LOS, lower oesophageal sphincter.
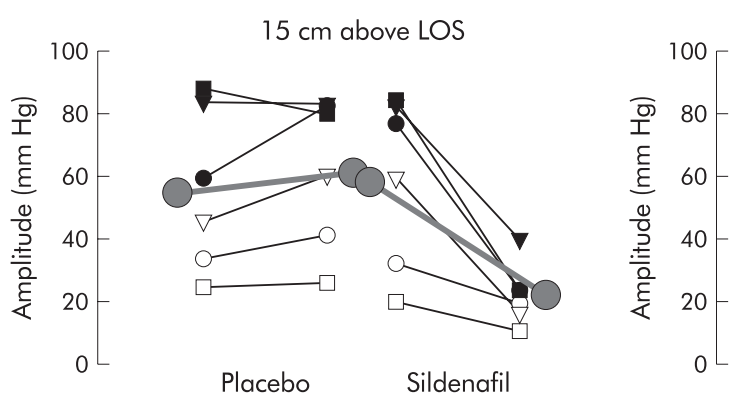

$20 \mathrm{~cm}$ above LOS
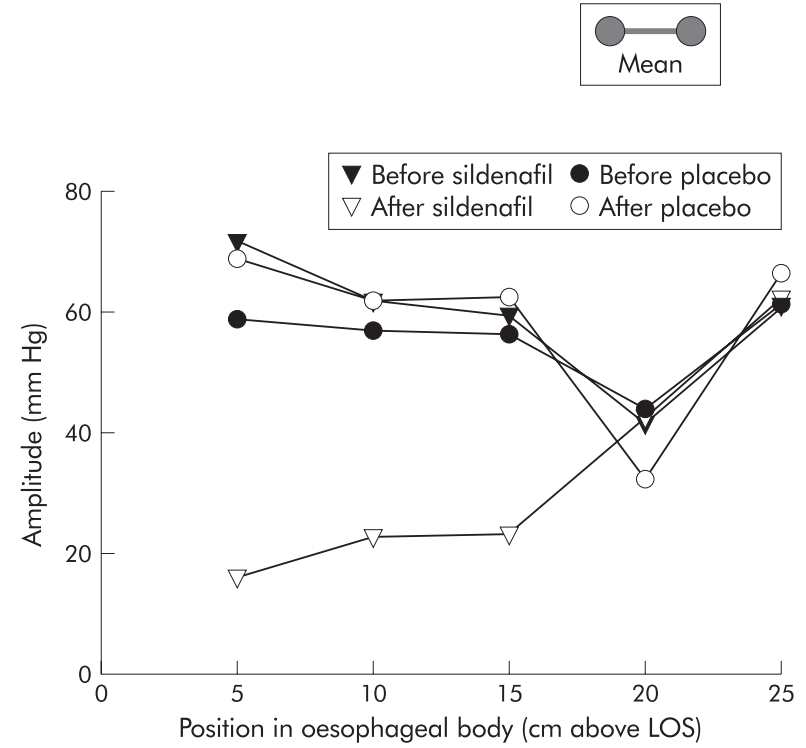

Figure 4 Amplitude of oesophageal contractions in six normal subjects at different levels, before and after placebo or sildenafil.

probe one hour after ingestion of sildenafil. One of the 11 patients (patient No 9 in table 1) in whom no manometric changes were seen after one hour, received another dose of $50 \mathrm{mg}$ sildenafil by gastric tube; measurements were repeated 30 minutes later.

After the manometry study we supplied the patients with sildenafil on an as needed basis. Patients were allowed to take one tablet of sildenafil $50 \mathrm{mg}$ once a day to control their symptoms. In the event of a good response or side effects, patients could reduce the dose of sildenafil to $25 \mathrm{mg}$ once a day. Patients were asked to keep a diary to document effects and side effects.

The study was approved by the Institutional Review Board of Karl-Franzens University.

\section{RESULTS}

Normal subjects

Stationary manometry

Figure 1 shows a typical example of manometric tracings and the LOS vector profile before and after sildenafil. Changes in

manometry readings were so obvious that in all cases the type of treatment could be determined by the examiner who was blinded and initially unaware of the administered substance. Results in the six normal subjects before and after ingestion of placebo or sildenafil are summarised in figs $2-4$. As shown in fig 2, there were no significant changes in LOS vector volume after ingestion of placebo whereas one hour after sildenafil all subjects showed a significant decrease. Mean basal pressure of the LOS did not change after placebo (14.0 (SD 2.6) $\mathrm{mm} \mathrm{Hg}$ before $v 12.9(3.3) \mathrm{mm} \mathrm{Hg}$ after placebo) but decreased significantly from 15.5 (4.8) to $9.2(2.5) \mathrm{mm} \mathrm{Hg}$ after sildenafil .

Amplitudes of the pressure waves during swallowing were assessed at 5, 10, 15, 20, and if available, at $25 \mathrm{~cm}$ above the LOS. Readings at the $25 \mathrm{~cm}$ level were available only in four subjects; in the other two subjects the upper oesophageal sphincter had already been reached at this level. As shown in fig 3, placebo had no significant effect on the pressure amplitude of oesophageal contractions. Sildenafil resulted in a significant decrease in pressure amplitude at 5, 10, and $15 \mathrm{~cm}$ above the LOS. In some cases there was almost complete abolition of peristalsis. Sildenafil slightly increased pressure amplitudes in the proximal oesophagus (striated muscle) at a level of $20 \mathrm{~cm}$ above the LOS in five of six subjects. Although this increase was slight and probably clinically irrelevant, it was statistically significant.

Figure 4 summarises the mean amplitudes in the oesophageal body after wet swallows between 5 and $25 \mathrm{~cm}$ above the LOS. Basal and placebo studies showed the physiological decrease in amplitudes at $20 \mathrm{~cm}$ above the LOS compared with the lower parts of the oesophageal body. Figure 4 also demonstrates that the relatively and absolutely largest inhibitory effects of sildenafil occurred in the lowest part of the oesophageal body.

With regard to the time needed for swallow propagation in the oesophageal body, there were no differences in the time required for amplitude propagation between two neighbouring $5 \mathrm{~cm}$ segments before and after placebo or sildenafil (data not shown).

No side effects were observed during the manometric studies. Systolic and diastolic arterial pressures measured prior to and one hour after sildenafil showed no differences. Following 


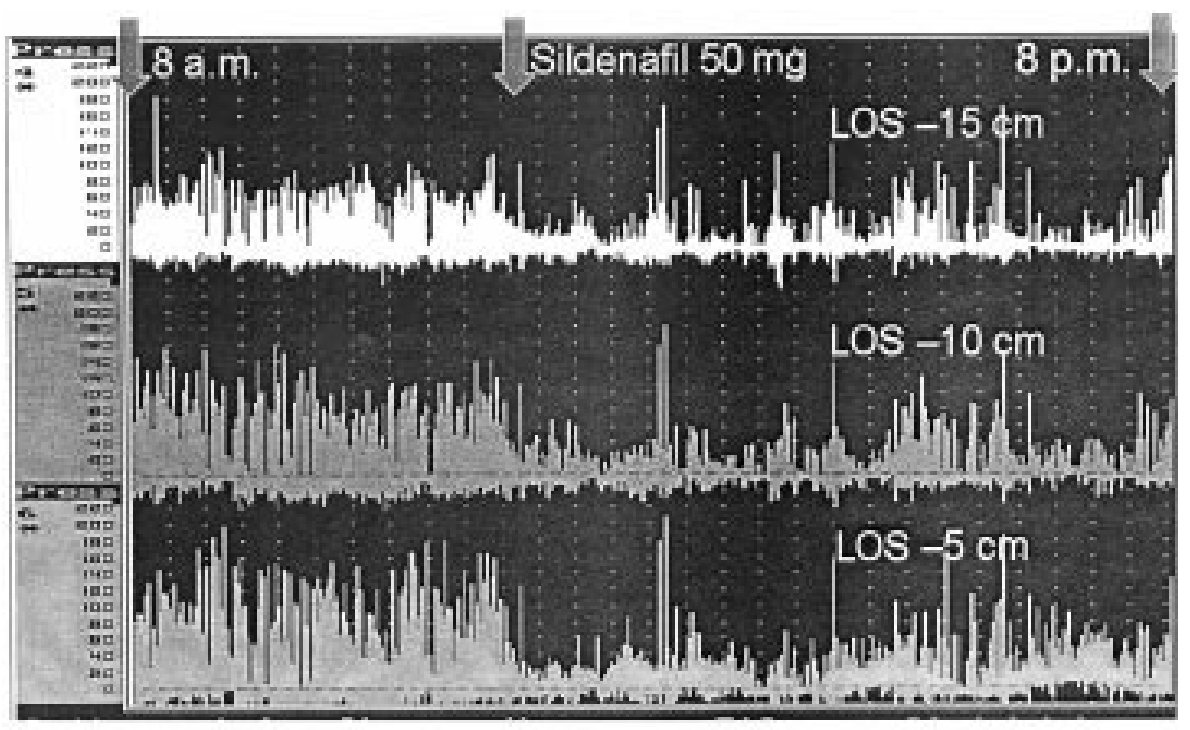

Figure 5 Oesophageal manometry of one subject over a 12 hour period. There was an obvious decrease in pressure amplitudes after sildenafil.

the studies, two subjects reported tolerable headaches after sildenafil and one subject reported a feeling of tachycardia after placebo. When volunteers were asked to guess which drug they thought they had actually received, they were correct four out of six times after placebo and three out of six times after sildenafil.

\section{Long term manometry}

An example of a long term manometry study is shown in fig 5. In this example it is obvious that spontaneous swallow amplitudes in the oesophageal body clearly decreased after sildenafil and remained low until bed rest. There was large intraindividual variability in contractile activity on the two study days and within a study day during the control periods before ingestion of sildenafil or placebo. Therefore, as described in the methods section, relative AIs were calculated in order to exclude the influence of diurnal variations on contractile activity. Figure 6 shows the relative hourly contractile activity indices of the oesophagus. In all subjects, sildenafil reduced spontaneous oesophageal activity compared with the respective time interval on the placebo day and compared with the control period before ingestion of sildenafil. In three subjects activity remained lower compared with the placebo day until the study was terminated eight hours after ingestion of sildenafil. In one subject activity increased dramatically towards the evening compared with the placebo day, and he reported considerable irritation of the throat due to the manometry tube during the course of the sildenafil day.

\section{Patients}

Table l summarises the patient characteristics, manometric features prior to and one hour after sildenafil, and the effect of sildenafil prescribed on an as needed basis. Eleven patients were evaluated. The major presenting symptoms were dysphagia and heartburn. Based on the results of oesophageal manometry, we diagnosed four patients with nutcracker oesophagus, two with oesophageal spasms, two with hypertensive LOS, and three with achalasia. In two patients (Nos 2 and 9) sildenafil caused no manometric changes; one of these patients was diagnosed as having diffuse oesophageal spasm and the other achalasia. All other patients showed considerable changes which are described in table 1.

When sildenafil was given on an as required basis to nine patients who showed manometric improvement, oesophageal symptoms improved in four (one patient with hypertensive LOS, one patient with oesophageal spasm, two patients with nutcracker oesophagus). None of the patients with achalasia

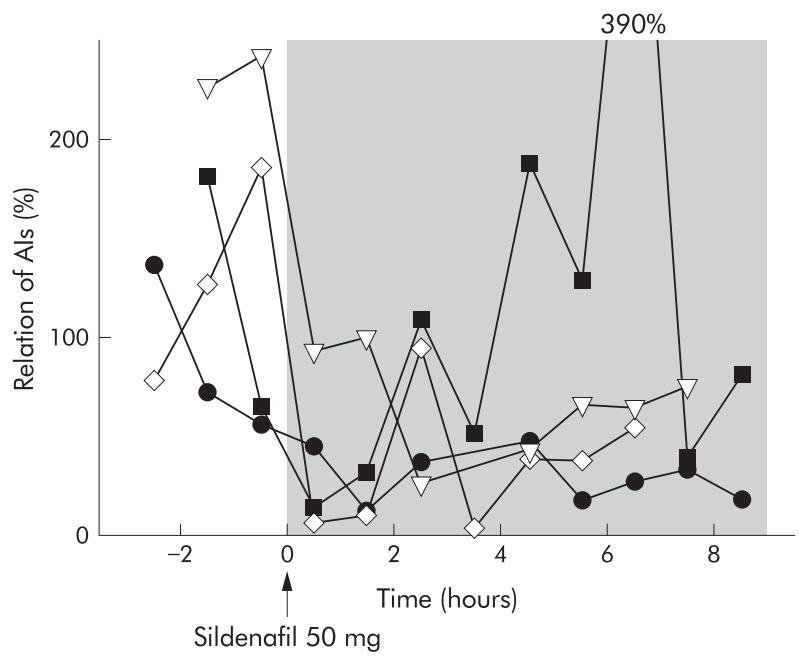

Figure 6 Relation of activity indices (Al) of corpus motility (sildenafil day $v$ control day) during long term oesophageal motility studies. Als during each hour of the studies on the control day are defined as $100 \%$. Als for each hour on the sildenafil day were related to the Als of the respective hours on the control day. Values below $100 \%$ denote relatively lower spontaneous contractile activity on the sildenafil day.

showed improvement in oesophageal symptoms. Two patients whose oesophageal symptoms improved refused to continue sildenafil because of sleep disturbances or a feeling of tightness in the chest. Furthermore, three of five patients who did not respond developed side effects such as dizziness and headache. Finally, there were two patients with marked clinical benefit and minimal or no side effects; both patients were female. Patient No 5 is free of symptoms on $25 \mathrm{mg}$ sildenafil once a day with immediate relapse when she discontinues the drug. In this case, manometry studies were repeated four months after initiation of therapy and showed the same qualitative features as before. Patient No 10 tolerated sildenafil better than diltiazem, which was prescribed by her family doctor. After four weeks however she discontinued sildenafil because she did not like the idea of becoming dependent on this drug.

\section{DISCUSSION}

Our results showed that in normal human subjects, augmentation of the effect of NO through activation of the NO-cGMP 
pathway with sildenafil had a clear effect on the lower oesophageal body and the LOS. In the oesophageal body, sildenafil reduced the amplitude of peristaltic contractions but did not influence the propagation speed of peristalsis. The effects were most pronounced in the most distal part of the oesophageal body. There was no inhibitory effect in the upper part of the oesophageal body. In contrast, our data suggest that there may even be a slight and probably clinically insignificant stimulatory effect in the upper part of the body of the oesophagus. Sildenafil reduced basal pressure and sphincter volume of the LOS. Our long term studies showed that the inhibitory effect of sildenafil started about 30 minutes after ingestion of the drug and lasted up to eight hours. Our observation that the inhibitory effect of sildenafil was abolished and oesophageal motility was actually stimulated in one subject who was irritated by the manometry probe on the sildenafil day, suggests that the inhibitory effect of the NO-cGMP pathway can be overridden by other stimulatory effects. This may also explain the differences in duration of the effect of sildenafil in patients with achalasia ${ }^{15}$ and in normal subjects ${ }^{19}$ reported by Bortolotti et al compared with our subjects. Some subjects or patients in Bortolotti's studies may have contributed to large variability, and this may have been the reason that significant differences beyond one hour could not be observed between the groups.

While we studied the consequences of augmenting the effect of NO in the human oesophagus, previously published studies on the role of NO in normal human subjects have so far been limited to testing the consequences of reducing the effect of NO by either inhibiting its synthesis with L-NMMA ${ }^{1012}$ or, in the case of Murray et al, decreasing its effect through inactivation by absorption to recombinant human haemoglobin $(\mathrm{rHb}){ }^{9} \mathrm{rHb}$ has been demonstrated to produce an increase in amplitude and speed of peristaltic contractions, and sometimes simultaneously occurring contractions, accompanied by retrosternal pain. ${ }^{9}$ L-NMMA has been demonstrated to increase peristaltic velocity in the proximal oesoph$\operatorname{agus}^{10}{ }^{12}$; however, increased peristaltic amplitude was seen in Hirsch's studies ${ }^{12}$ whereas Konturek et al could not find a change in peristaltic amplitude caused by L-NMMA. ${ }^{10}$ Results with regard to the effect of L-NMMA and $\mathrm{rHb}$ on LOS are contradictory. Whereas Hirsch et al could not demonstrate an effect of L-NMMA, Murray et al reported inhibition of swallow induced relaxation of the LOS due to $\mathrm{rHb}$. Differences in the effects of rHb and L-NMMA were suggested to be due to different involvement of central and peripheral mechanisms. Sildenafil does not have central effects; thus we can postulate that the effects reported in our study were only peripheral.

With regard to the LOS, studies with sildenafil and $\mathrm{rHb}$ suggest that NO is involved in LOS relaxation. The effect of sildenafil can be interpreted as demonstrating a direct role of the NO-cGMP pathway in the LOS whereas the effect of L-NMMA can be interpreted as demonstrating a role for the swallow associated coordination process resulting in sphincter relaxation. Again, these differences may be due to different actions on central and peripheral pathways.

Our data, as well as data obtained with rHb and L-NMMA, demonstrated that $\mathrm{NO}$ was involved in the regulation of the amplitude of contractions. Activation of NO results in a decrease, and inactivation an increase, in peristaltic amplitude. Peristaltic velocity can be increased over control conditions by inhibiting the effect of $\mathrm{NO}$ with $\mathrm{rHb}$ and L-NMMA but it cannot be decreased compared with control conditions by augmenting the effect of NO with sildenafil. This discrepancy between our studies and those with rHb and L-NMMA indicates that modulation of $\mathrm{NO}$ activity in normal subjects only can accelerate but not decelerate peristaltic velocity compared with control conditions. In contrast, it may also be the result of the action of rHb and L-NMMA on central mechanisms controlling peristaltic velocity.
Studies with the NO donor nitroglycerine given sublingually have shown only a transient decrease in LOS basal pressure lasting just a few minutes with no changes in oesophageal body motility of healthy subjects. ${ }^{20}$ Long acting nitrates produced no change in any parameter of oesophageal motility. ${ }^{20}$ Another approach which has been used to increase endogenous sources of NO was long term oral intake of L-arginine..$^{21}$ This resulted in a decrease in basal postprandial LOS pressure but did not change motility in the oesophageal body.

Based on our results in normal subjects, we hypothesise that sildenafil may reduce elevated oesophageal amplitude or LOS pressure in motility disorders such as nutcracker oesophagus, oesophageal spasms, hypertensive LOS, or achalasia, and that patients may benefit symptomatically if treated with sildenafil on an as needed basis. In fact, we were able to demonstrate an effect of sildenafil on manometric characteristics of their disorders in 9/11 patients. In two patients, one with oesophageal spasm and one with achalasia, no effect was demonstrated although the sildenafil dose was doubled in one instance. It is not clear why sildenafil did not have demonstrable effects in these two patients. However, it is conceivable that in the non-responding achalasia patient there was no intrinsic NO activity left, and the NO-cGMP pathway therefore could not be activated. A possible explanation for the lack of effect in one of the patients with oesophageal spasm could be that another motility activating stimulus overruled the inhibitory effect of NO.

Four of nine patients who had manometric improvement also showed improvement in oesophageal symptoms although two decided not to continue treatment because of side effects. Patients who showed an improvement in oesophageal symptoms on sildenafil included patients with hypertensive LOS, oesophageal spasm, and nutcracker oesophagus. For selected patients with these motility disorders, sildenafil may be an alternative to treatment with calcium antagonists or nitrates because the systemic effects of these substances are similar and individual susceptibility may favour sildenafil over the other drugs. Currently, we do not know how to identify in advance patients who might respond to the treatment.

Our group included three patients with achalasia. Two of these had a considerable decrease in basal LOS pressure after sildenafil but none had clinical improvement while taking sildenafil on an as needed basis. The most likely reason for this lack of clinical effectiveness is that the balance between decreased contractile activity in the oesophageal body and increased pressure with lack of relaxation of the LOS is not influenced by sildenafil. This can be demonstrated by the results in patient No 2 in whom although LOS basal pressure was inhibited there was also a decrease in oesophageal amplitude to a similar extent, so that the relation between the amplitude of contractions in the oesophageal body and LOS pressure did not change. Bortoletti et al have recently reported results of studies with sildenafil in achalasia patients. They demonstrated manometric findings similar to ours but provided no information on symptoms in their patients. Our explanation for the clinical ineffectiveness of sildenafil is that the relation between abnormal LOS and motility in the body of the oesophagus is not influenced by sildenafil. We also applied this supposition to Bortolotti's published data. In Bortolotti's patients LOS tone, LOS residual pressure, and pressure wave amplitude decreased by $67 \%, 68 \%$, and $72 \%$, respectively, in the postinfusion period and by $48 \%, 53 \%$, and $51 \%$, respectively, for nadir values. This clearly demonstrates that in Bortolitti's patients, pressure waves in the oesophageal body and LOS pressure were also influenced proportionally. Therefore, the relation between amplitude of oesophageal contractility and LOS pressure is not changed by sildenafil compared with placebo, and no clinical effect can be expected.

Achalasia has been demonstrated to result from a defect in NO neurones. ${ }^{16}$ Reduction in LOS pressure in achalasia therefore may be seen as a substitution for this defect. The role of 
nitrergic neurones in hypertensive LOS, oesophageal spasm, and nutcracker oesophagus has not been established. It is therefore unclear whether the beneficial effects of sildenafil in these diseases are the result of substitution of a deficiency state or a consequence of pharmacological stimulation of the oesophagus.

In conclusion, sildenafil lowers LOS pressure and propulsive forces in the oesophageal body in healthy subjects as well as in patients with nutcracker oesophagus, hypertensive LOS, and achalasia. The effect of sildenafil on the oesophageal body may last for eight hours in healthy volunteers. Despite a good manometric response in the majority of patients with oesophageal spasm, hypertensive LOS, or nutcracker oesophagus only a minority of patients showed clinical improvement with sildenafil administered on an as needed basis. Furthermore, side effects due to sildenafil are a limitation.

\section{ACKNOWLEDGEMENT}

The authors thank Eugene Lamont for critical reading of the manuscript.

\section{Authors' affiliations}

A J Eherer, I Schwetz, H F Hammer, T Petnehazy, S J Scheidl, K Weber, G J Krejs, Department of Internal Medicine, Karl-Franzens University, Graz, Austria

\section{REFERENCES}

1 Sanders KM, Ward SM. Nitric oxide as a mediator of non-adrenergic, non- cholinergic neurotransmission. Am J Physiol 1995;489:735-43.

2 Koh SD, Campbell JD, Carl A, et al. Nitric oxide activates multiple potassium channels in canine colonic smooth muscle. J Physiol 1995:489:735-43.

3 Goldstein I, Lue TF, Padma-Nathan $\mathrm{H}$, et al. Oral sildenafil in the treatment of erectile dysfunction. N Engl J Med 1998;338: 1397-404

4 Moreland RB, Goldstein I, Traish A. Sildenafil, a novel inhibitor of phosphodiesterase type 5 in human corpus cavernosum muscle cells. Life Sci 1998;62:309-18.
5 Boolell M, Allen MJ, Ballard S, et al. Sildenafil: An orally active type 5 cyclic GAIP specific phosphodiesterase inhibitor for the treatment of
penile erectile dysfunction. Int J Impot Res 1996;8:47-52.

6 Wallis RM, Corbin JD, Francis SH, et al. Tissue distribution of phosphodiesterase families and the effect of sildenafil on tissue cyclic nucleotides, platelet function, and the contractile responses of trabeculae carneae and aortic rings in vitro. Am J Cardiol 1999:83:3-12C.

7 Du C, Murray J, Conklin JL. Cyclic GMP mediates nitric oxide produced NANC hyperpolarization of opossum esophageal circular smooth muscle. Gastroenterology 1992;102:443A

8 Tottrup MA, Knudsen MA, Madse G, et al. The role of the L-arginine-nitric oxide pathway for relaxation of the human lower esophageal sphincter. Gastroenterology 1992;102:527A.

9 Murray JA, Ledlow A, Launspach J, et al. The effects of recombinant human hemoglobin on esophageal motor function in humans. Guman hemoglobin on esophageal mo

10 Konturek JW, Thor P, Lukaszyk A, et al. Endogenous nitric oxide in the control of esophageal motility in humans. J Physiol Pharmacol 1997:48:201-9.

11 Anand N, Paterson WG. Nitric oxide (NO) is the mediator of physiological lower esophageal sphincter relaxation (LESR) in vivo. Gastroenterology 1992;102:415A

12 Hirsch DP, Holloway RH, Tytgat GN, et al. Involvement of nitric oxide in human transient lower esophageal sphincter relaxations and esophageal primary peristalsis. Gastroenterology 1998;1 15:1374-80.

13 Anand N, Paterson WG. Role of nitric oxide in esophageal peristalsis. Am J Physiol 1994;266:G123-31.

14 Yamato S, Spechler JS, Goyal RK. Role of nitric oxide in esophageal peristalsis in the opossum. Gastroenterology 1992;103:197-204.

15 Bortolotti M, Mari C, Lopilato C, et al. Effects of sildenafil on esophageal motility of patients with idiopathic achalasia. Gastroenterology 2000;1 18:253-7.

16 Hirano I. Pathophysiology of achalasia. Curr Gastroenterol Reports 1999; 1:198-202

17 Katz PO, Castell JA. Nonachalasia motility disorders. In: Castell DO, Richter JE, eds. The esophagus, 3rd edn. Philadelphia: Lippincott, Williams \& Wilkins, 1999:215-34

18 Wong RKH, Maydonovith CL. Achalasia. In: Castell DO, Richter JE, eds. The esophagus, 3rd edn. Philadelphia: Lippincott, Williams \& Wilkins, 1999: 185-213.

19 Bortolotti M, Lopilato C, Porrazzo G, et al. Effect of sildenafil on esophageal motility. Gastroenterology 2000;1 18:A854.

20 Kikendall JW, Mellow MH. Effect of sublingual nitroglycerin and long-acting nitrate preparations on esophageal motility. Gastroenterology 1980;79:703-6.

21 Luiking YC, Weusten BL, Portincasa $\mathrm{P}$, et al. Effects of long-term oral L-arginine on esophageal motility and gallbladder dynamics in healthy humans. Am J Physiol 1998;274:G984-91. 